\title{
Membrane topology analysis of the Escherichia coli cytosine permease
}

\author{
Steffen Danielsen, ${ }^{1}$ Dana Boyd ${ }^{2}$ and Jan Neuhard' \\ Author for correspondence: Jan Neuhard. Tel: +4535 322007. Fax: +4535322040 . \\ e-mail: neuhard@mermaid.molbio.ku.dk
}

\author{
1 Department of Biological \\ Chemistry, Institute of \\ Molecular Biology, \\ University of Copenhagen, \\ Sølvgade 83H, DK-1307, \\ Copenhagen K, Denmark \\ 2 Department of \\ Microbiology and \\ Molecular Genetics, \\ Harvard Medical School, \\ Boston, MA 02115, USA
}

\begin{abstract}
The Escherichia coli codBA operon encodes cytosine permease (CodB) and cytosine deaminase (CodA). CodB mediates uptake of exogenously supplied cytosine, and CodA catalyses the hydrolytic deamination of cytosine to uracil and ammonia. The hydropathic profile of CodB indicates that it is an integral cytoplasmic membrane protein possessing several transmembrane-spanning domains. The membrane topology of CodB was investigated by using gene fusions containing varying lengths of the amino-terminus of CodB fused to either alkaline phosphatase (AP) or $\beta$-galactosidase (BG). The AP activities expressed by the CodB-AP fusions are consistent with a topological model in which the amino- and the carboxy-termini of CodB are located in the cytoplasm, and in which CodB possesses 12 membrane-spanning segments. The enzyme activities of most of the CodB-BG fusions support the model. However, the results obtained with some of the CodB-BG fusions illustrate the limitations of using BG as a reporter protein in studies of membrane protein topology.
\end{abstract}

Keywords: cytosine permease, membrane protein topology, gene fusion, pho $A, \operatorname{lac} Z$

\section{INTRODUCTION}

The only known route by which cytosine can be metabolized is via hydrolytic deamination, catalysed by cytosine deaminase (Cod $\mathrm{A})$, to yield uracil and ammonia. $\operatorname{CodA}$ is found in a number of bacteria and fungi (Esders \& Lynn, 1985; Hoeprich et al., 1974; Ipata et al., 1971; Katsuragi et al., 1986; Sakai et al., 1975; West et al., 1982), but is absent from mammalian cells (Koechlin et al., 1966). The $\operatorname{cod} A$ gene, encoding $\operatorname{Cod} \mathrm{A}$, is the second gene in the $\operatorname{cod} B A$ operon located close to the lac operon at $8 \mathrm{~min}$ on the Escherichia coli chromosome (De Haan et al., 1972). The first gene in the operon, $\operatorname{cod} B$, encodes cytosine permease (CodB), a membrane protein responsible for transport of cytosine across the cytoplasmic membrane (Danielsen et al., 1992). Mutants deficient in uptake of cytosine, i.e. codB mutants, have been selected as clones resistant to low concentrations of the toxic cytosine analogue 5-fluorocytosine (Lind et al., 1973). Pyrimidinerequiring $\operatorname{codB}$ mutants cannot grow with low concentrations of cytosine as sole pyrimidine source. E. coli $\operatorname{cod} A$

\footnotetext{
Abbreviations: AP, alkaline phosphatase; BG, $\beta$-galactosidase; CodA, cytosine deaminase; CodB, cytosine permease; XP, 5-bromo-4-chloro-3indolyl phosphate.

The SwissProt accession number for the sequence data reported in this paper is P25525.
}

cod $B^{+}$mutants are capable of concentrating externally applied cytosine 200 -fold, and this capacity is further increased 10-fold when $\operatorname{codB}$ is present in multicopies on a plasmid (Danielsen et al., 1992).

The use of gene fusion techniques has expanded our understanding of the organization of proteins in the lipid bilayer of the bacterial cytoplasmic membrane (for recent reviews see Boyd, 1994; Hennessey \& Broome-Smith, 1993; Traxler et al., 1993). The first reporter protein used specifically for the study of membrane protein topology was the periplasmic alkaline phosphatase (AP) from $E$. coli, encoded by the pho $A$ gene (Boyd et al., 1987; Manoil \& Beckwith, 1986; Manoil et al., 1988, 1990). Other reporter proteins include TEM $\beta$-lactamase encoded by the bla gene (Broome-Smith et al., 1990) and E. coli $\beta$ galactosidase (BG) encoded by lac $Z$ (Froshauer et al., 1988).

The important property of AP is that it is enzymically active only when it is translocated through the cytoplasmic membrane into the periplasmic space. If mutations or gene fusions cause AP to be retained in the cytoplasm it is enzymically inactive, probably because formation of the intrachain disulphide bonds, essential for enzymic activity, does not occur in this compartment (Derman et al., 1993 a). When AP is fused to a membrane protein, the topogenic information present in the domain 
to which the fusion is made determines the ultimate cellular location of AP (Manoil \& Beckwith, 1986). Consequently, when AP is fused to a membrane protein it results in low enzymic activity if the fusion junction is in a cytoplasmic domain, and high activity if it is located in a periplasmic domain.

A reverse pattern of enzyme activities is observed when BG is used as a reporter protein (Froshauer et al., 1988; Lee et al., 1989). Fused to a protein export signal, such as a periplasmic domain of a cytoplasmic membrane protein, BG becomes embedded in an enzymically inactive form in the cytoplasmic membrane during the translocation process. However, if the fusion occurs to a cytoplasmic domain BG will be attached to the carboxy-terminal end of the preceding transmembrane segment, and will be facing the cytoplasm in an enzymically active form. Thus the combined use of AP and BG fusions represents an efficient system for analysis of membrane protein topology (Manoil, 1990).

In the present paper the membrane topology of CodB has been studied by gene fusions to both AP and BG.

\section{METHODS}

Materials and culture conditions. Luria broth (LB) and M63 minimal medium were used as growth media (Miller, 1972). With M63, glucose $\left(2 \mathrm{mg} \mathrm{ml}^{-1}\right)$ was used as carbon source. When required, supplements were added at the following final concentrations: thiamin, $1 \mu \mathrm{g} \mathrm{ml}^{-1}$; Casamino acids, $2 \mathrm{mg} \mathrm{ml}^{-1}$; ampicillin, $30 \mu \mathrm{g} \mathrm{ml} l^{-1}$; chloramphenicol, $30 \mu \mathrm{g} \mathrm{ml}^{-1}$. The chromogenic indicators for AP, 5-bromo-4-chloro-3-indolyl phosphate (XP) (Bachem), and for BG, X-Gal (Sigma), were used at a final concentration of $40 \mu \mathrm{g} \mathrm{ml}^{-1}$. L- $\left[{ }^{35} \mathrm{~S}\right]$ Methionine (1000 Ci mmol $^{-1} 37 \mathrm{TBq}^{\mathrm{mmol}}{ }^{-1}$ ) was obtained either from New England Nuclear or from Amersham. Rabbit anti-AP serum was prepared by C. Gardel, and rabbit anti-OmpA serum was a generous gift from C. Kumamoto.
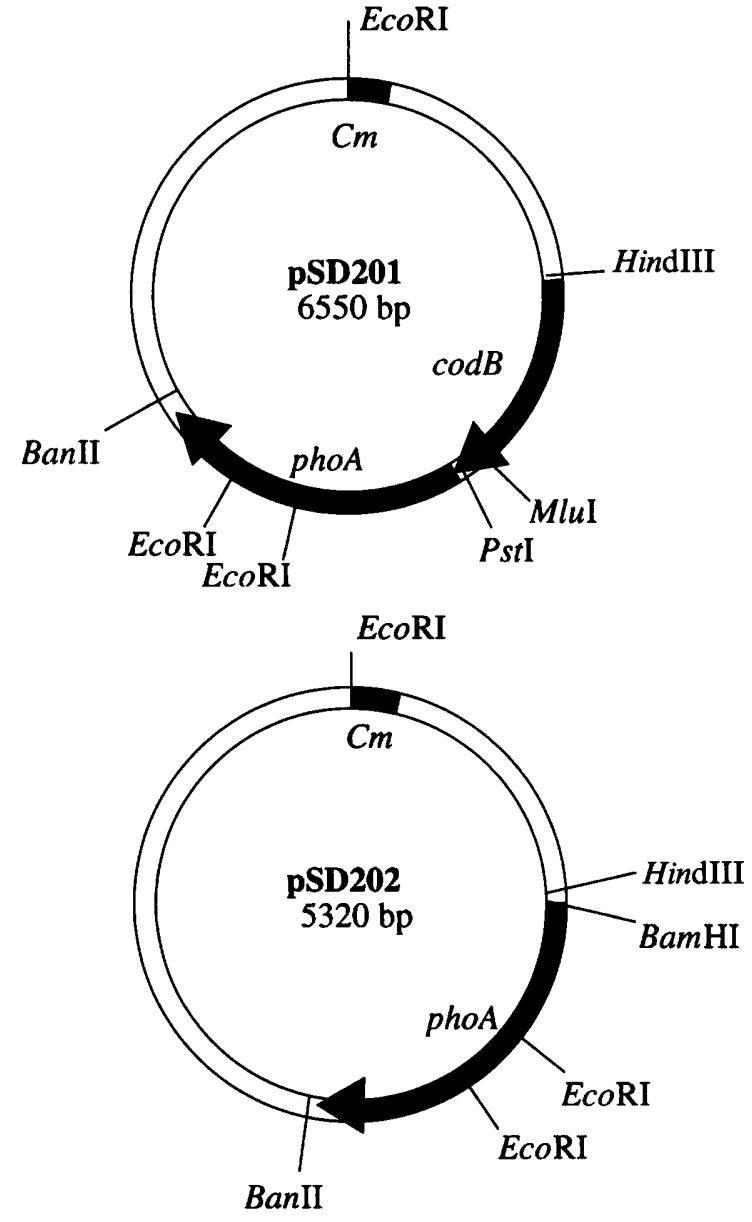

Fig. 1. Maps of plasmids pSD201 and pSD202. Plasmids were constructed as described in Methods. PSD201 was used for construction of $\operatorname{codB} B$ phoA fusions by exonuclease III and pSD202 was used as a cloning host for PCR-amplified codB fragments.

Table 1. E. coli strains and plasmids

\begin{tabular}{|c|c|c|}
\hline Strain or plasmid & Genotype & Reference or source \\
\hline \multicolumn{3}{|l|}{ Strain } \\
\hline DHB4 & $\begin{array}{l}\mathrm{F}^{\prime} \text { lac pro lac } \mathrm{I}^{\mathrm{q}} / \Delta(\text { ara leu }) 7697 \text { araD } 139 \\
\Delta(\text { lac }) \mathrm{X} 74 \text { galE galK } \text { ppsL phoR } \Delta(\text { pho } A) \\
\text { PvuII }\end{array}$ & Boyd et al. (1987) \\
\hline $\mathrm{DH} 5 \alpha$ & $\begin{array}{l}\text { end } A 1 \text { bsd } 17\left(\mathrm{r}_{\mathrm{K}}^{-} \mathrm{m}_{\mathrm{K}}^{+}\right) \sup E 44 \text { thi-1 } \operatorname{rec} A 1 \\
\operatorname{gyr} A\left(\mathrm{Nal}^{\mathrm{r}}\right) \operatorname{rel} A 1 \Delta(\operatorname{lac} Z Y A-\arg F) \mathrm{U} 169 \\
\operatorname{deo} \mathrm{R}[\phi 80 \operatorname{dlac} \Delta(l a c Z) \mathrm{M} 15]\end{array}$ & Woodcock et al. (1989) \\
\hline \multicolumn{3}{|c|}{ 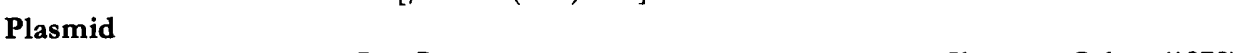 } \\
\hline pACYC184 & $\mathrm{Cm}^{\mathrm{R}} \mathrm{Tc}^{\mathrm{R}}$ & Chang \& Cohen (1978) \\
\hline pJEL247 & $\mathrm{R} 1$ derivative carrying lac $Z$ & Valentin-Hansen (1986) \\
\hline pUI310 & pUC19 derivative carrying $p h o A$ & Varga \& Kaplan (1989) \\
\hline pSD112 & $\begin{array}{l}\text { pBR322 derivative carrying the } E \text {. coli } \operatorname{codB} A \\
\text { operon }\end{array}$ & Danielsen et al. (1992) \\
\hline pSD200 & pUC19 derivative carrying codB-pho $A$ genes & This study \\
\hline pSD201 & pACYC derivative carrying $\operatorname{cod} B-p h o A$ genes & This study \\
\hline pSD202 & pACYC derivative carrying $p h o A$ & This study \\
\hline
\end{tabular}


Table 2. CodB-AP fusion primers

\begin{tabular}{|c|c|c|}
\hline Sequence $\left(5^{\prime} \rightarrow 3^{\prime}\right)^{*}$ & Resulting construct $\nmid$ & Fusion no. $\ddagger$ \\
\hline ataatgga TCCCCCACCTTTTTGC & $\operatorname{CodB}_{\text {com }}$ & - \\
\hline gccggatccgg T'TTCCGCGCCGAC'T & $\mathrm{CodB}_{\text {Lys-018 }}$ & 1 \\
\hline gcgggatccggATCATGATAGCTAAGAC & $\operatorname{CodB}_{\text {Asp -051 }}$ & 2 \\
\hline gttggatccggTAGCAGTGAAGGCAG & CodB $_{\text {Leu-100 }}$ & 3 \\
\hline tccggatccggTGCCTTACCCACCG & $\operatorname{CodB}_{\mathrm{Ala}-123}$ & 4 \\
\hline accggatccggCGAAATGCCAAAAAAGAC & $\operatorname{CodB}_{\text {Ser-148 }}$ & 5 \\
\hline gcgggatccggATCTAACGGTTGTGCG & $\operatorname{CodB}_{\text {Asp-192 }}$ & 7 \\
\hline agcggatccggTTTGGCAT'TGCGAC & CodB $_{\text {Lys-222 }}$ & 8 \\
\hline gcaggatccggATCAGAGATATCCGC & CodB $_{\text {Asp-257 }}$ & 13 \\
\hline gggttggatccggCATCCCGGTAATGTT & CodB $_{\text {Met-297 }}$ & 15 \\
\hline cagggatceggATTGTTATACAGCCATAA & $\operatorname{CodB}_{\text {Asn-320 }}$ & 16 \\
\hline aattgggatccggCAT ACGCGTGGTCGC & $\operatorname{CodB}_{\text {Met- } 358}$ & 21 \\
\hline accggatccggTCCCGGTAACCAGTG & $\operatorname{CodB}_{\mathrm{Gly}-381}$ & 22 \\
\hline gtaggatccggTTCGACACTGTTAGCCTCC & CodB $_{\text {Glu-419 }}$ & 23 \\
\hline
\end{tabular}

* Letters in uppercase represent $\operatorname{codB}$ residues. Underlined bases show the BamHI linker introduced in all amplified fragments to facilitate the subsequent cloning; the last $\operatorname{cod} B$ codon present in the amplified fragment is shown in bold next to the proline codon (italics) introduced to give all fusions the same linker region. Note that the sequence of all primers, except $\operatorname{CodB}_{\text {com }}$, is complementary to the sense strand of codB.

$\dagger$ Last CodB residue present in the amplified fragment.

$\ddagger$ Number of the resulting constructs refers to Table 3 and Fig. 3 .

Recombinant DNA techniques and sequencing. DNA manipulations, transformations, restriction analysis and gel purification of DNA fragments were performed by standard procedures according to Sambrook et al. (1989). Enzymes for molecular cloning and restriction analysis were obtained from Promega or New England Biolabs. DNA sequence analysis was accomplished by the chain-termination method of Sanger et al. (1977) using double-stranded plasmid DNA template. Oligonucleotides used for sequencing of the $\operatorname{codB}-$ pho $A$ and $\operatorname{cod} B-\operatorname{lac} Z$ fusion junctions were 5'-ATCACGCAGAGCGGCAGTCTGAT-3' (pho $A$ ) and 5'-CGCCAGGGTTTTCCCAGTCACGA-3' (lacZ).

Bacterial strains and vectors. Bacterial strains and plasmids are listed in Table 1. Plasmid PSD112, which was used for PCR amplification of $\operatorname{codB}$ fragments, is described elsewhere (Danielsen et al., 1992). Plasmid pUI310 (Varga \& Kaplan, 1989 ) is a pUC19 derivative that carries a multiple cloning site in front of the coding region for signal-less AP and was a gift. Plasmid pACYC184 was from New England Biolabs. Plasmid pJEL247 (Valentin-Hansen, 1986) is a single copy miniderivative of $\mathrm{R} 1$, used in the construction of the $\operatorname{codB}-\operatorname{lac} Z$ fusions and was a gift.

\section{Plasmid constructions}

pSD200. A $1.5 \mathrm{kbp}$ fragment containing the $\operatorname{codB}$ gene was obtained by PCR amplification using PSD112 as template and the following primers: 5'-TTACACCGATAAGCT'TTCCCCC- $3^{\prime}$, which introduces a HindIII site in the $5^{\prime}$ end of the amplified fragment, and 5'-GCCACAGCCCCTCTTCGCCTGG-3'. The amplified fragment was subsequently cloned as a HindIII/PstI fragment into HindIII/PstI-digested pUI310.

pSD201 (Fig. 1). The entire $\operatorname{cod} B-p h o A$ region of pSD200 was cloned as a $2 \cdot 8 \mathrm{kbp}$ HindIII/BanII fragment into HindIII/BanIIdigested pACYC184.

pSD202 (Fig. 1). The pho $A$ region of pUI310 was cloned as a HindIII/BanII fragment into HindIII/BanII-digested PACYC184.
Amplification of DNA. PCR (Saiki et al., 1988) was performed on a DNA Thermal Cycler (Perkin Elmer) using Vent DNA polymerase (New England Biolabs). Reactions were done in a final volume of $100 \mu \mathrm{l}$ using the buffer recommended by the supplier and 2.5 U DNA polymerase, $50 \mathrm{ng}$ template, $100 \mathrm{pmol}$ of each oligonucleotide primer and $25 \mathrm{nmol}$ of each of the four dNTPs.

Enzyme assays on whole cells. Fresh stationary-phase cultures in LB were diluted 100 -fold, grown for $3 \mathrm{~h}$ at $37^{\circ} \mathrm{C}$, harvested, and permeabilized by SDS/chloroform treatment (Miller, 1972). AP activity was assayed by measuring the rate of $p$-nitrophenyl phosphate hydrolysis (Manoil, 1991). To prevent spontaneous activation of low-activity AP fusions in non-growing cells 1 $\mathrm{mM}$ iodoacetamide was routinely added prior to assay (Derman et al., 1993b). BG activity was assayed by measuring the rate of hydrolysis of o-nitrophenyl galactoside (Miller, 1972).

Construction of gene fusions by exonuclease III nested deletions. CsCl-purified plasmid pSD201 (Fig. 1) was digested with restriction endonucleases $M l u \mathrm{I}$ and PstI, phenol/ chloroform extracted, ethanol precipitated and redissolved. Unidirectional deletions were generated by digestion with exonuclease III essentially as described by Sambrook et al. (1989). DNA was subsequently treated with mung bean nuclease and Klenow fragment to blunt-end the DNA, recircularized with T4 DNA ligase and transformed into DH5 $\alpha$. Transformants expressing high AP activity were selected as blue colonies on LB plates containing XP and chloramphenicol. Plasmid DNA from purified colonies was analysed by restriction endonuclease digestion and DNA sequencing.

Construction of gene fusions by use of PCR. DNA fragments including $85 \mathrm{bp}$ of the region $5^{\prime}$ of the $\operatorname{codB} A$ promoter and various amounts of the codB-coding region were generated by PCR, using the primers shown in Table 2 . All primers contained a BamHI site at the $5^{\prime}$ end. One primer, $\operatorname{codB}_{\text {com }}$, contained 
sequences corresponding to the region $85 \mathrm{bp}$ upstream of the $\operatorname{codB} A$ promoter, and was used together with each of the fusionpoint-specific primers designed to be complementary to the sequence of the desired fusion-point. A proline codon (CCG) was introduced in all the latter primers to ensure that all fusions had identical linker regions, i.e. CodB-Pro-Asp-Pro-Arg-AP. Following amplification, the PCR products were digested with $B a m \mathrm{HI}$ and cloned into the pACYC184-derived pho $A$ fusion vector $\mathrm{pSD} 202$ (Fig. 1). The resulting plasmids were transformed into DHB4 and $\mathrm{Cm}^{\mathrm{R}}$ transformants isolated. The fusion junction of each plasmid was verified by DNA sequencing. The linker sequences were chosen for convenience. The inclusion of an arginine residue in the linker might, in some cases, result in poor export of AP fused to a periplasmic domain with a weak export signal because positively charged residues can act as determinants of cytoplasmic localization (Boyd \& Beckwith, $1989,1990)$. In one instance, inclusion of a single arginine residue in a linker sequence did not interfere with reporting of topology (Prinz \& Beckwith, 1994).

The same PCR fragments used above for construction of the CodB-AP fusions were cloned as translational fusions with lac $Z$ in the low-copy-number fusion vector PJEL247. The resulting CodB-LacZ fusion proteins all had the following linker region: CodB-Pro-Asp-Pro-Ser-Thr-Ser-Thr-Gln-Ala-Cys-Asp-Pro-

LacZ. Plasmids were transformed into strain $\mathrm{DH} 5 \alpha$, and $\mathrm{Ap}^{\mathrm{R}}$ transformants were isolated. The fusion junction of each plasmid was verified by DNA sequencing.

Rate of hybrid protein synthesis. Cells expressing the fusions were grown to mid-exponential phase at $37^{\circ} \mathrm{C}$ in $\mathrm{M} 63$, supplemented with all common amino acids except methionine. At a cell density of approximately $10^{8}$ cells $\mathrm{ml}^{-1} \mathrm{~L}$ $\left[{ }^{35} \mathrm{~S}\right]$ methionine $\left(30 \mu \mathrm{Ci} \mathrm{m} \mathrm{m}^{-1} ; 1110 \mathrm{kBq} \mathrm{ml}^{-1}\right)$ was added to $1.5 \mathrm{ml}$ of the culture. After $60 \mathrm{~s}$, unlabelled methionine $(100 \mu \mathrm{g}$ $\mathrm{ml}^{-1}$ ) was added, and $750 \mu \mathrm{l}$ immediately withdrawn (pulse sample) for determination of the rate of protein synthesis as described by Manoil (1991). After $30 \mathrm{~min}$ a second sample (chase sample) was withdrawn for determination of the stability of the hybrid proteins. Immunoprecipitation was performed with antibodies to AP and OmpA (internal control) in the presence of the protease inhibitor PMSF $\left(150 \mu \mathrm{g} \mathrm{ml}^{-1}\right.$; Sigma). The precipitates were fractionated by SDS-PAGE (Laemmli, 1970 ), and the amount of radioactivity in the AP-specific and OmpA-specific polypeptides was quantified by a PhosphorImager. The amount of AP-specific radioactivity in the pulse samples, corrected for the number of methionine residues present in the fusion, was divided by that of OmpA and was used as a measure of the rate of synthesis of the fusion protein.

\section{RESULTS}

\section{Prediction of the transmembrane topology of CodB}

The alternating pattern of hydrophilic and hydrophobic segments seen in a hydropathy plot is a feature characteristic for membrane proteins with multiple membranespanning domains (Kyte \& Doolittle, 1982). Positions of putative transmembrane-spanning segments in the amino acid sequence of CodB were identified using TopPred II (Claros \& von Heijne, 1994), a computer program which generates the hydrophobic profile. Fig. 2 shows the hydropathy plot and indicates the position of 12 hydrophobic segments (I-XII) capable of spanning the cytoplasmic membrane. The prevalence of positively charged amino acid residues (arginine and lysine) in the first, third, seventh, eleventh and thirteenth hydrophilic segments of CodB suggests, in accordance with the so-called positive inside rule (von Heijne, 1992), that these segments are cytoplasmic loops. By alternating the orientation of the 12 hydrophobic segments a topological model can be generated in which the amino- and carboxy-termini of CodB are located in the cytoplasm.

\section{Construction of $\operatorname{cod} B-p h o A$ fusions}

Random CodB-AP fusions were generated in plasmid pSD201 by unidirectional exonuclease III digestion into the $3^{\prime}$ end of $\operatorname{codB}$ (Fig. 1, Methods). Following circularization the resulting plasmids were transformed into DHB4 and transformants expressing high levels of $A P$, due to in-frame fusions of AP to periplasmic domains of $\operatorname{CodB}$, were isolated as blue colonies on plates containing chloramphenicol and XP. Cells harbouring fusions with low AP activity cannot be distinguished from cells containing no fusions or out-of-frame fusions. Fifty transformants expressing high levels of AP were isolated. Sequencing of plasmid DNA from these transformants identified 10 different CodB-AP fusion points (Table 3).

To obtain a more complete set of CodB-AP fusions PCR was used to construct fusions in which the fusion-point was located at the carboxy-terminus of each hydrophilic region throughout CodB (Boyd et al., 1993). This will reduce the likelihood of isolating fusions expressing intermediate AP activities due to disruption of known topogenic determinants such as membrane-spanning segments or short hydrophilic segments with net positive charge (Boyd \& Beckwith, 1990; Calamia \& Manoil, 1990; Traxler et al., 1993). Following this rationale a total of 13 plasmid-borne CodB-AP fusions were constructed (Table 3) and transformed into DHB4.

\section{AP activities of CodB-AP fusions}

AP activity was measured in DHB4 expressing the various CodB-AP fusion proteins and the relative rate of synthesis of each fusion protein was determined by pulse-labelling (see Methods). By dividing the steady-state AP activity with the rate of synthesis of the fusion protein a normalized AP activity was obtained which reflected the potential of each fusion for AP translocation. The results are summarized in Table 3 , and the normalized AP activities of each fusion protein are shown in Fig. 3 superimposed on the 12-helical model for CodB. The observed enzyme activities correlate well with the proposed topological model; cells carrying fusions with the junction in, or near, the predicted periplasmic regions of CodB (hydrophilic loops 2, 4, 6, 8, 10 and 12) express AP activities $20-200$ times higher than those in which fusion junctions were in predicted cytoplasmic regions (hydrophilic loops 1, 3, 5, 7, 9, 11 and 13). Accordingly, colonies expressing fusions to predicted periplasmic regions were blue on plates containing $\mathrm{XP}$, whereas colonies expressing fusions to predicted cytoplasmic regions were white or pale blue. 


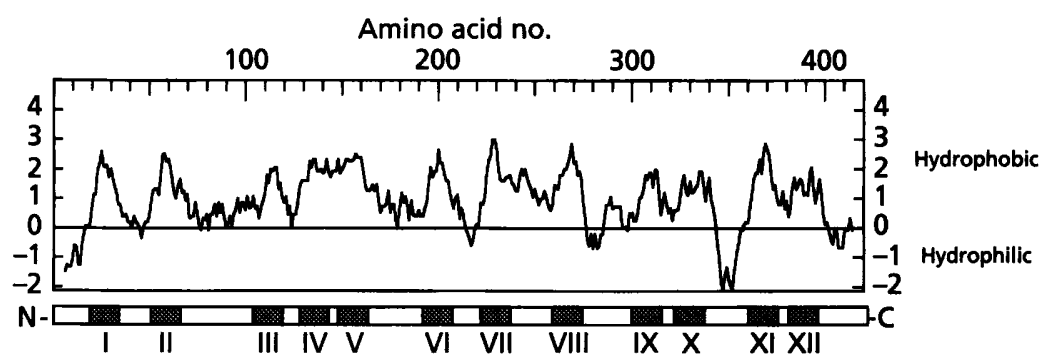

Fig. 2. Hydropathy plot of CodB from E. coli. Hydropathy analysis was performed as described by Claros \& von Heijne (1994), using a 19 amino acids moving window. The linear sequence of CodB is indicated below the hydropathy plot as a bar extending from the amino ( $\mathrm{N}$ )- to the carboxy (C)-terminus. The hatched boxes within the bar as well as the roman numerals below the bar indicate positions of putative transmembrane segments.

Table 3. AP and BG activities

\begin{tabular}{|c|c|c|c|c|c|c|}
\hline Fusion no. & $\begin{array}{l}\text { Last CodB } \\
\text { residue in fusion }\end{array}$ & $\begin{array}{l}\text { Method of } \\
\text { construction }\end{array}$ & $\begin{array}{l}\text { Steady-state } \\
\text { AP activity* }\end{array}$ & $\begin{array}{c}\text { Relative CodB-AP } \\
\text { synthesis rate } f\end{array}$ & $\begin{array}{l}\text { Normalized } \\
\text { AP activity } \ddagger\end{array}$ & $\begin{array}{l}\text { BG enzyme } \\
\text { activity } \\
end{array}$ \\
\hline 1 & Lys-018 & PCR & $4 \cdot 2$ & 13 & 0.4 & 210 \\
\hline 2 & Asp-051 & PCR & 500 & 12 & 50 & $4 \cdot 9$ \\
\hline 3 & Leu-100 & PCR & $<0.2$ & $1 \cdot 2$ & $0 \cdot 3$ & 23 \\
\hline 4 & Ala-123 & PCR & 50 & 1.5 & 40 & $0 \cdot 4$ \\
\hline 5 & Ser-148 & PCR & 0.4 & 0.8 & 0.6 & 36 \\
\hline 6 & Asp-181 & ExolII & 39 & $1 \cdot 2$ & 39 & - \\
\hline 7 & Asp-192 & PCR & 10 & $0 \cdot 8$ & 15 & 14 \\
\hline 8 & Lys-222 & PCR & 0.3 & $1 \cdot 3$ & 0.3 & 14 \\
\hline 9 & Leu-234 & ExolII & 60 & 0.9 & 80 & - \\
\hline 10 & Ile-241 & ExoIII & 67 & 1 & 80 & - \\
\hline 11 & Gly-243 & ExoIII & 67 & 1 & 80 & - \\
\hline 12 & Gly-246 & ExolII & 69 & $1 \cdot 2$ & 69 & - \\
\hline 13 & Asp- 257 & PCR & 84 & 1 & 100 & $<0.2$ \\
\hline 14 & Gly-263 & ExolII & 63 & 1 & 75 & - \\
\hline 15 & Met-297 & PCR & 0.9 & 0.8 & $1 \cdot 4$ & 51 \\
\hline 16 & Asn-320 & PCR & 63 & $0 \cdot 8$ & 94 & 0.4 \\
\hline 17 & Gly-323 & ExollI & 69 & 1 & 82 & - \\
\hline 18 & Ser-329 & ExoIII & 52 & $1 \cdot 1$ & 59 & - \\
\hline 19 & Ala-330 & ExolII & 47 & 0.8 & 70 & - \\
\hline 20 & Ile-332 & ExoIII & 43 & 0.8 & 63 & - \\
\hline 21 & Met-358 & PCR & 0.5 & 0.6 & 1 & 54 \\
\hline 22 & Gly-381 & PCR & 60 & 0.7 & 98 & $<0.2$ \\
\hline 23 & Glu-419 & PCR & 0.6 & $1 \cdot 3$ & 0.6 & 84 \\
\hline
\end{tabular}

* Measured in permeabilized cells and given as nmol NPP hydrolysed $\min ^{-1} \mathrm{OD}_{600}{ }^{-1}$. Values represent the mean of four to six independent determinations.

†Determined by pulse-labelling as described in Methods. Values are expressed relative to the rate determined for CodB ${ }_{257}-\mathrm{AP}$.

$\ddagger$ Calculated by dividing the value for steady-state AP activity (column four) with the relative CodB-AP synthesis rate (column five), and expressed relative to the value for the $\mathrm{CodB}_{257}-\mathrm{AP}$ fusion, set at 100 .

$\S$ Mean of four to six independent determinations, expressed in Miller units.

\section{CodB-BG fusions}

To investigate whether the use of BG as reporter protein would indicate a similar topological structure of CodB, the same PCR fragments which were used for the construction of AP fusions were cloned into the lowcopy-number lac $Z$ fusion vector pJEL247 (ValentinHansen, 1986). The resulting plasmids were transformed into DH5 $\alpha$, and the level of BG activity expressed by the fusion proteins was measured. The results are shown in Table 3.

\section{DISCUSSION}

In the present study, the membrane topology of the E. coli $\operatorname{CodB}$, a protein involved in the active transport of the pyrimidine base cytosine, has been examined. Based on a computer-generated hydropathic profile, which takes into account the distribution of positively charged amino acids, a topological working model was generated. To test the model a total of 23 different plasmid-borne $\operatorname{cod} B-p h o A$ fusions and 13 different $\operatorname{cod} B-l a c Z$ fusions were constructed, which contained various amounts of the amino- 
(a)

\section{Periplasm}

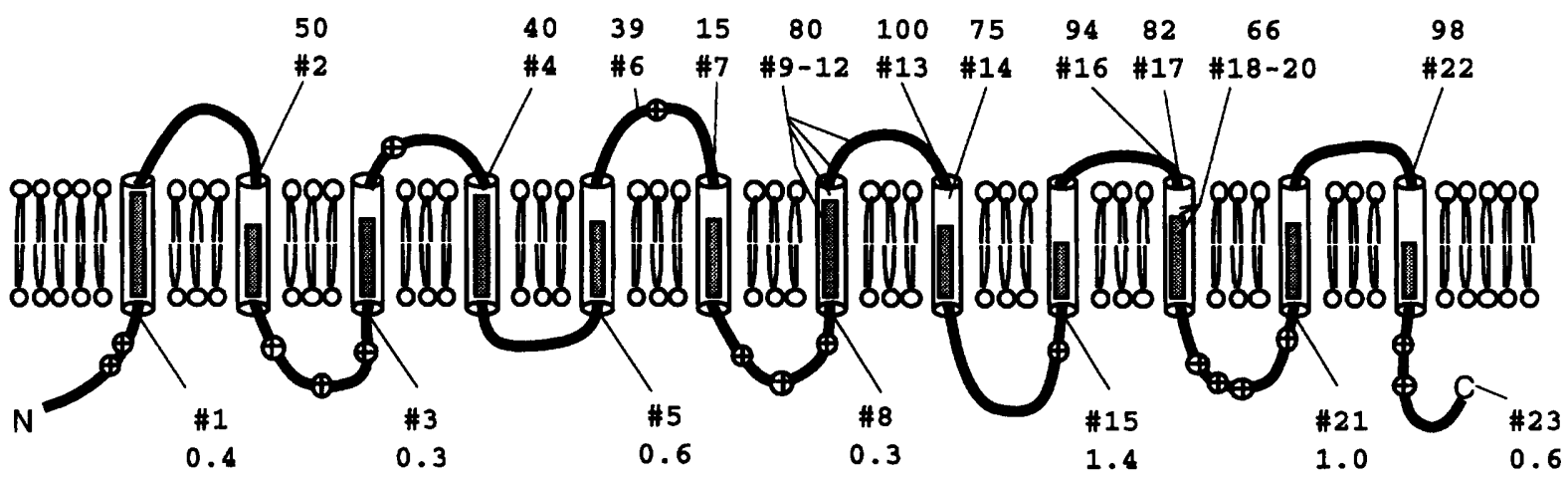

(b)

\section{Cytoplasm}

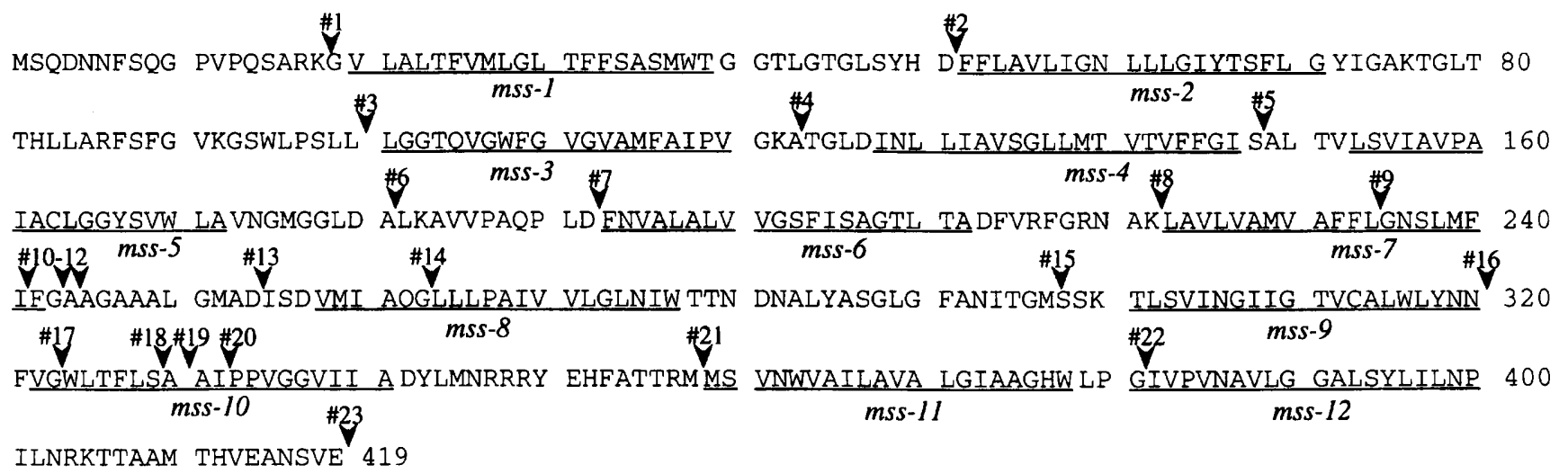

Fig. 3. Topological model of CodB in the $E$. coli inner membrane, and positions of fusions to CodB. (a) Putative membrane-spanning segments are shown as cylinders. The height of the bars inside the cylinders indicates the relative hydrophobicity of the segment. Thick lines symbolize hydrophilic segments. +, Arginine or lysine residue. Thin lines indicate fusion points. The number and the normalized AP activity of the fusion is shown. For fusions 9-12 and 18-20 the mean AP values are given; the individual values are listed in Table 3. (b) Amino acid sequence of CodB. Arrows point to the position of individual fusions. The putative membrane-spanning segments (mss) are underlined and numbered.

terminus of CodB fused in-frame to AP or BG, respectively. Close correlation was found between the predictions made from the model and the observed AP activities of the CodB-AP fusions. When AP was fused to the hydrophilic domains $2,4,6,8,10$ and 12 , the resulting fusion proteins exhibited high enzymic activity. These domains were predicted to face the periplasmic space in the native protein, and the high levels of AP indicate that the preceding transmembrane segments promote efficient translocation of AP into the periplasmic space. AP fusions to the carboxy-terminal end of the hydrophilic domains 1 , $3,5,7,9,11$ and 13 result in hybrid proteins exhibiting considerably lower AP activity, suggesting that these domains in CodB are facing the cytoplasm. The alternative explanation for the low activity of the latter fusions, that they might be synthesized at lower levels than the high activity fusions, was ruled out by measuring the rate of synthesis by pulse-labelling (Table 3 ). With the exceptions noted below, all fusions were synthesized at similar levels and the normalized activities do not suggest a different topology.

All CodB-AP fusion proteins were equally unstable and almost completely degraded after a 30 min chase (data not shown). A similar pattern of uniform instability is rarely observed with $\operatorname{Tn} P h o A$-generated fusions to other membrane proteins. It could reflect the instability of $\operatorname{CodB}$ itself, or be caused by the linker sequences, i.e. Pro-AspPro-Arg or Thr-Leu-Glu-Asp-Pro-Arg for the PCR- and exonuclease-III-derived fusions, respectively. Two patterns of degradation were observed. Hybrid proteins with the fusion junction in putative cytoplasmic domains (low-activity fusions) were completely degraded, presumably because AP moieties located in the cytoplasm lack functional conformation. In contrast, hybrid proteins with junctions in putative periplasmic domains (high 
activity fusions) always yielded an AP-sized fragment that remained stable during the chase. This may be due to rapid translocation of the AP moiety of these latter fusions. Once exported, the AP part will be protease resistant, enzymically active and hence detectable by antiAP immunoprecipitation (Traxler et al., 1992).

Fusion of AP or BG to residues 18 and 51 of CodB resulted in unexpectedly high levels of enzyme activity (Table 3). The pulse-label experiment indicated that the rate of synthesis of $\mathrm{CodB}_{018}-\mathrm{AP}$ and $\mathrm{CodB}_{051}-\mathrm{AP}$ was significantly higher than that of all later fusions. A computer search of the $\operatorname{cod} B$ sequence, using the program 'Terminator' (Brendel \& Tifonov, 1984; Devereux et al., 1984) identified a putative weak transcriptional terminator at a position corresponding to codons $76-91$, which could explain the observed step-down in expression level. A step-down in the amount of fusion protein has also been observed with the E. coli MalF protein (Boyd et al., 1987; Froshauer $e t$ al., 1988). In that case the preceding protein in the same operon, MalE, is produced at much higher levels. The different rates of synthesis of early and late MalF-AP fusions may indicate that the signal responsible for the step-down is at least partially within the malF gene.

According to the model, residue 192 in CodB is located at the end of the third periplasmic domain. However, the normalized activity of $\mathrm{CodB}_{192}-\mathrm{AP}$ (no. 7, Table 3) is only 15 units, i.e. approximately $20 \%$ of the activity observed for the other periplasmic domain hybrids. The assignment of this domain to the periplasm appears to be correct, since the enzyme level of cells expressing $\operatorname{CodB}_{181}-\mathrm{AP}$ (fusion no. 6, Table 3) is almost as high as the other periplasmic domain hybrids. Several factors may contribute to the inefficiency by which the AP moiety of $\mathrm{CodB}_{192}-\mathrm{AP}$ is translocated across the membrane. One is that the membrane-spanning segment preceding the fusion point of $\mathrm{CodB}_{192}-\mathrm{AP}$, is one of the least hydrophobic in the protein. Another may be the positive charges on $\mathrm{Lys}_{183}$ and on the Arg residue of the linker. This is supported by the higher activity observed with fusion $\mathrm{CodB}_{181}-\mathrm{AP}$ from which Lys ${ }_{183}$ is absent. Finally the cytoplasmic domain immediately preceding the $\mathrm{CodB}_{192}$-AP fusion protein contains no obvious topogenic determinant, such as positively charged residues. Thus, efficient translocation of this domain, in the wildtype protein, may require $\mathrm{CodB}$ sequences absent in the fusion protein, i.e. information present in the distal part of CodB. A somewhat similar observation was reported for the $E$. coli lactose permease where the ninth membranespanning segment was a less potent export signal than the other membrane-spanning segments, and it was proposed that coinsertion of the ninth and tenth membranespanning segments was required for efficient translocation of the intervening periplasmic domain (Calamia \& Manoil, 1990).

Conflicting results have been reported when BG has been used as reporter protein in studies of membrane protein topology (Froshauer et al., 1988; Georgiou et al., 1988; Gött \& Boos, 1988). The topology for CodB was investigated using a set of CodB-BG fusions, in which the ends of all hydrophilic CodB domains were fused to BG. With the exceptions noted below the BG level for these fusions supported the topological structure as predicted by the AP fusions. BG fused to the end of hydrophilic domains $1,3,5,9,11$ and 13 resulted in hybrid proteins expressing high BG activity, whereas fusions to the end of hydrophilic domains $2,4,8,10$ and 12 resulted in hybrid proteins expressing low BG activity. The fusion point of $\mathrm{CodB}_{192}-\mathrm{BG}$ is located at the end of the sixth hydrophilic domain, believed to be periplasmic, and should therefore express BG at low levels. The relatively high BG activity observed for this fusion is in accordance with the low activity of the homologous $\mathrm{CodB}_{192}-\mathrm{AP}$ fusion, and supports the proposed poor export competence of the fifth membrane-spanning segment. At present there is no obvious explanation for the low activity observed for $\operatorname{CodB}_{222}-\mathrm{BG}$, in which BG is fused at the end of the seventh hydrophilic domain. If the topology analysis of CodB had been based entirely on the results obtained with BG as the reporter protein it would have been impossible to assign a cellular location to the sixth and seventh hydrophilic domains of CodB.

To our knowledge this is the first topological structure reported for a membrane protein involved in prokaryotic pyrimidine metabolism. Reports on the topology of other membrane proteins related to nucleotide metabolism comes from studies on the yeast uracil permease (Silve et al., 1991).

\section{ACKNOWLEDGEMENTS}

We would like to thank Jon Beckwith for encouragement, support and reading of the manuscript. This work was supported by grants from The Danish Center for Microbiology (S.D. and J.N.), The Danish Research Council (S.D.), The National Science Foundation (D. B.), and NIH (Jon Beckwith).

\section{REFERENCES}

Boyd, D. (1994). Use of gene fusions to determine membrane protein topology. In Membrane Protein Structure: Experimental Approaches, pp. 144-163. Edited by S. H. White. New York: Oxford University Press.

Boyd, D. \& Beckwith, J. (1989). Positively charged amino acid residues can act as topogenic determinants in membrane proteins. Proc Natl Acad Sci USA 86, 9751-9754.

Boyd, D. \& Beckwith, J. (1990). The role of charged amino acids in the localization of secreted and membrane proteins. Cell 62, 1031-1033.

Boyd, D., Manoil, C. \& Beckwith, J. (1987). Determinants of membrane protein topology. Proc Natl Acad Sci USA 84, 8525-8529.

Boyd, D., Traxler, B. \& Beckwith, J. (1993). Analysis of the topology of a membrane protein by using a minimum number of alkaline phosphatase fusions. $J$ Bacteriol 175, 553-556.

Brendel, V. \& Tifonov, E. N. (1984). A computer algorithm for testing potential prokaryotic terminators. Nucleic Acids Res 12, 4411-4430.

Broome-Smith, J. K., Tadayyon, M. \& Zhang, Y. (1990). Beta- 
lactamase as a probe of membrane protein assembly and protein export. Mol Microbiol 4, 1637-1644.

Calamia, J. \& Manoil, C. (1990). Lac permease of Escherichia coli: topology and sequence elements promoting membrane insertion. Proc Natl Acad Sci US A 87, 4937-4941.

Chang, A. C. Y. \& Cohen, S. N. (1978). Construction and characterization of amplifiable multicopy DNA cloning vehicles derived from the P15A cryptic miniplasmid. J Bacteriol 134, 1141-1156.

Claros, M. G. \& von Heijne, G. (1994). Prediction of transmembrane segments in integral membrane proteins, and the putative topologies, using several algorithms. CABIOS 10, 685-686.

Danielsen, S., Kilstrup, M., Barilla, K., Jochimsen, B. \& Neuhard, J. (1992). Characterization of the Escherichia coli $\operatorname{codB} A$ operon encoding cytosine permease and cytosine deaminase. Mol Microbiol 6, 1335-1344.

De Haan, P. G., Felix, H. S. \& Peters, R. (1972). Mapping of the gene for cytosine deaminase on the Escherichia coli chromosome. Antonie Leeuwenboek 38, 257-263.

Derman, A. I., Prinz, W. A., Belin, D. \& Beckwith, J. (1993a). Mutations that allow disulfide bond formation in the cytoplasm of Escherichia coli. Science 262, 1744-1747.

Derman, A. I., Puziss, J. W., Bassford, P. J. \& Beckwith, J. (1993 b). A signal sequence is not required for protein export in $\operatorname{prl} A$ mutants of Escherichia coli. EMBO J 12, 879-888.

Devereux, J., Haeberli, P. \& Smithies, O. (1984). A comprehensive set of sequence analysis programs for the VAX. Nucleic Acids Res 12, 387-395.

Esders, T. W. \& Lynn, S. Y. (1985). Purification and properties of creatinine iminohydrolase from Flavobacterium filamentosum. $J$ Biol Cbem 260, 3915-3922.

Froshauer, S., Green, G. N., Boyd, D., McGovern, K. \& Beckwith, J. (1988). Genetic analysis of the membrane insertion of MalF, a cytoplasmic membrane protein of Escherichia coli. $J$ Mol Biol 200, 501-511.

Georgiou, C. D., Dueweke, T. J. \& Gennis, R. B. (1988). Betagalactosidase gene fusions as probes for the cytoplasmic regions of subunits I and II of the membrane-bound cytochrome d terminal oxidase from Eschericbia coli. J Biol Chem 263, 13130-13137.

Gott, P. \& Boos, W. (1988). The transmembrane topology of the snglycerol-3-phosphate permease of E. coli analysed by pho $A$ and lac $Z$ fusions. Mol Microbiol 2, 655-663.

von Heijne, G. (1992). Membrane protein structure prediction. Hydrophobicity analysis and the positive-inside rule. J Mol Biol 225, 487-494.

Hennessey, E. S. \& Broome-Smith, J. K. (1993). Gene-fusion techniques for determining membrane-protein topology. Curr Opin Struct Biol 3, 524-531.

Hoeprich, P. D., Ingraham, J. L., Kleker, E. \& Winship, M. J. (1974). Development of resistance to 5-fluorocytosine in Candida parapsilosis during therapy. $J$ Infect Dis 130, 112-118.

Ipata, P. L., Marmocchi, F., Magni, G., Feliciolo, R. \& Polidoro, G. (1971). Baker's yeast cytosine deaminase. Some enzymic properties and allosteric inhibition by nucleosides and nucleotides. Biochemistry 10, 4270-4276.

Katsuragi, T., Sakai, T., Matsomuto, K. \& Tonomura, K. (1986). Cytosine deaminase from Escherichia coli. Production, purification, and some characteristics. Agric Biol Chem 50, 1721-1730.

Koechlin, B. A., Rubio, F., Palmer, S., Gabriel, T. \& Duschinsky, R. (1966). The metabolism of 5 -fluorocytosine- ${ }^{14} \mathrm{C}$ and of cytosine${ }^{14} \mathrm{C}$ in the rat and the disposition of 5 -fluorocytosine $-2{ }^{14} \mathrm{C}$ in man. Biocbem Pharmacol 15, 435-446.
Kyte, J. \& Doolittle, R. F. (1982). A simple method for displaying the hydropathic character of a protein. J Mol Biol 157, 105-132.

Laemmli, U. K. (1970). Cleavage of structural proteins during the assembly of the head of bacteriophage T4. Nature 227, 680-685.

Lee, C., Li, P., Inouye, H., Brickman, E. R. \& Beckwith, J. (1989). Genetic studies on the inability of $\beta$-galactosidase to be translocated across the Escherichia coli cytoplasmic membrane. J Bacteriol 171, 4609-4616.

Lind, R. M., Sukhodolets, V. V. \& Smirnov, Y. O. (1973). Mutations affecting deamination and transport of cytosine in Escherichia coli. Genetika 9, 116-121.

Manoil, C. (1990). Analysis of protein localization by the use of gene fusions with complementary properties. I Bacteriol 172, 1035-1042.

Manoil, C. (1991). Analysis of membrane protein topology using alkaline phosphatase and $\beta$-galactosidase gene fusions. Methods Cell Biol 34, 61-75.

Manoil, C. \& Beckwith, J. (1986). A genetic approach to analyzing membrane protein topology. Science 233, 1403-1408.

Manoil, C., Boyd, D. \& Beckwith, J. (1988). Molecular genetic analysis of membrane protein topology. Trends Genet 4, 223-226.

Manoil, C., Mekalanos, J. J. \& Beckwith, J. (1990). Alkaline phosphatase fusions: sensors of subcellular location. J Bacteriol 172, 515-518.

Miller, J. H. (1972). Experiments in Molecular Genetics. Cold Spring Harbor, NY: Cold Spring Harbor Laboratory.

Prinz, W. \& Beckwith, J. (1994). Gene fusion analysis of membrane protein topology: a direct comparison of alkaline phosphatase and $\beta$-lactamase fusions. $J$ Bacteriol 176, 6410-6413.

Saiki, R. K., Gelfand, D. H., Stoffel, S., Scharf, S. J., Higuchi, R., Horn, G. T., Mullis, K. B. \& Erlich, H. A. (1988). Primer-directed enzymatic amplification of DNA with a thermostable DNA polymerase. Science 239, 487-491.

Sakai, T., Yu, T., Tabe, H. \& Omata, S. (1975). Purification of cytosine deaminase from Serratia marcescens. Agric Biol Chem 39, 1623-1629.

Sambrook, J., Fritsch, E. F. \& Maniatis, T. (1989). Molecular Cloning: a Laboratory Manual. Cold Spring Harbor, NY : Cold Spring Harbor Laboratory.

Sanger, F., Nicklen, S. \& Coulson, A. R. (1977). DNA sequencing with chain-terminating inhibitors. Proc Natl Acad Sci USA 74, 5463-5467.

Silve, S., Volland, C., Garnier, C., Jund, R., Chevallier, M. R. \& Haguenauer-Tsapis, R. (1991). Membrane insertion of uracil permease, a polytopic yeast plasma membrane protein. Mol Cell Biol $11,1114-1.24$.

Traxler, , Lee, C., Boyd, D. \& Beckwith, J. (1992). The dynamics of assembly of a cytoplasmic membrane protein in Escherichia coli. $J$ Biol Chem 267, 5339-5345.

Traxler, B., Boyd, D. \& Beckwith, J. (1993). The topological analysis of integral cytoplasmic membrane proteins. J Membr Biol 132, 1-11.

Valentin-Hansen, P. V. (1986). DNA-protein recognition, demonstration of three genetically separated operator elements that are required for repression of the Escherichia coli deoC $A B D$ promoters by the DeoR repressor. EMBO J 5, 2015-2021.

Varga, A. R. \& Kaplan, S. (1989). Construction, expression, and localization of a $C y c A::$ Pho $A$ fusion protein in Rhodobacter sphaeroides and Escherichia coli. J Bacteriol 171, 5830-5839.

West, T. P., Shanley, M. S. \& O'Donovan, G. A. (1982). Purification 
and some properties of cytosine deaminase from Salmonella typhimurium. Biochim Biophys Acta 719, 251-258.

Woodcock, D. M., Crowther, P. J., Doherty, J., Jefferson, S., DeCruz, E., Noyer-Weidner, M., Smith, S. S., Michael, M. Z. \&

Graham, M. W. (1989). Quantitative evaluation of Escherichia coli host strains for tolerance to cytosine methylation in plasmid and phage recombinants. Nucleic Acids Res 17, 3469-3478.

Received 4 April 1995; revised 26 June 1995; accepted 10 July 1995. 